\title{
Actively and passively aspirated temperature sensors in a windless environment like greenhouses
}

\author{
NIKHILESH TUMULURU RAMESH*(B) and JAYWANT H ARAKERI \\ Department of Mechanical Engineering, Indian Institute of Science, Bangalore 560 012, India \\ e-mail: nikhilesh.tumuluru@gmail.com; jaywant@mecheng.iisc.ernet.in
}

MS received 1 September 2018; revised 1 November 2018; accepted 19 December 2018; published online 25 March 2019

\begin{abstract}
Windless environments are prevalent in greenhouses, where precise temperature control is critical to the health of plants and errors in temperature measurement must be avoided. A mathematical model based on heat balance is used to estimate the error in temperature sensors under different conditions and sensor geometries. The model is then applied to two geometries and solved numerically. The sensors used are a T-type thermocouple and a Sensirion SHT 75. Experiments are carried out in a greenhouse prototype to replicate conditions in a greenhouse and validate the error model. Active ventilation of the sensors is provided by a fan and passive ventilation is provided using a model built on the concept of a 'solar chimney'. It is shown that even small flow rates can decrease the error shown by unventilated sensors by as much as $10^{\circ} \mathrm{C}$.
\end{abstract}

Keywords. Solar chimney; temperature sensors; aspiration; heat transfer; thermocouple; greenhouse.

\section{Introduction}

It is well established that sensors produce errors while measuring the temperature of air if they are exposed to direct radiation [1-3]. The various energy interactions between the sensor and its surroundings dictate the final temperature of the sensor. The error in the temperature readings depends on several factors, including the sensor size, emissivity, thermal mass, air flow over the sensor and the shape of the sensor. A common practice to reduce errors in temperature measurement is to employ radiation shields, whose effect on temperature and humidity sensors have been studied extensively. There are different types of radiation shields [4] and they can be mechanically aspirated or passively ventilated. These types of shields include single plate, double plate, stacked multiple plates or vertical tubes.

It is important in temperature measurement that the temperature sensor be well ventilated even after shielding it from direct radiation, because over long periods of time, the combined effect of conduction from the radiation shield and longwave radiation tends to heat up the stagnant air inside the shield to a temperature higher than the ambient. Air flow around the sensors is thus required. However, in environments like greenhouses, air movement may not always be present, thus making sensors more error prone.

In this work, theory and experiments have been combined to show the effect of shielding and ventilation on the

*For correspondence error shown by a sensor. The shielding configuration used is a horizontal tube as detailed in [3]. A mathematical model is used to calculate the temperature that a sensor measures in different conditions, namely, unshielded as well as shielded and aspirated. Two types of sensors have been used. The first is the T-type thermocouple, which has a small diameter $(1 \mathrm{~mm})$ and a small thermal mass. The second sensor modelled is the Sensirion SHT 75 sensor, which measures both temperature as well as humidity. Experiments are then carried out using both active ventilation by use of a fan and passive ventilation by use of a mini-solar chimney. The Sensirion sensor was chosen as it is currently adopted in many applications for temperature and humidity measurements.

\section{Mathematical model}

\subsection{Energy balance for sensors}

The thermocouple without shielding can be modelled as either a horizontal cylinder (for thermocouples with length comparably higher than the diameter) or a sphere. The incoming solar insolation $(I)$ is balanced by the heat lost due to convection and radiation.

$$
I A_{p} \alpha=U A\left(T_{s s}-T_{a}\right) .
$$

The Nusselt number correlation for natural convection in a horizontal cylinder/sphere has been used to calculate $h$.

The Sensirion sensor is modelled as a flat plate. The actual sensor is shown in figure 1. Equation (1) is also valid 


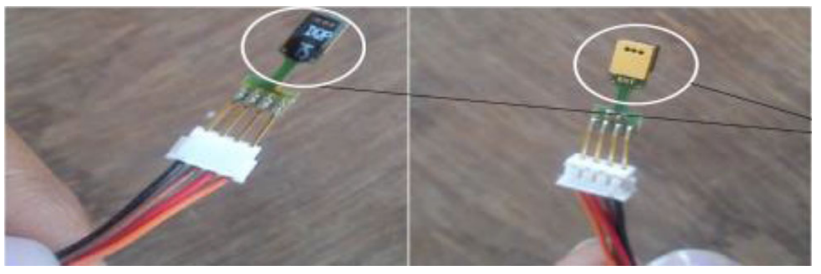

Figure 1. Sensirion sensor modelled as a flat plate.

for this case with the appropriate Nusselt number correlation.

Table 1 presents the errors shown by the two sensors when they are kept in a still atmosphere, i.e., without any shield or flow.

For a sensor enclosed within a shield and subjected to forced ventilation, there are multiple energy interactions. Consider a horizontal PVC tube which encloses a sensor. The size of the sensor is negligible compared to the size of the shield. The PVC tube is padded with thermocol to provide insulation and is wrapped in aluminium foil to increase reflectivity. A small fan is attached to the end of the PVC tube which can generate different flow rates through the tube. A schematic of the set-up is shown in figure 2 .

In steady state, the outside surface of the shield is directly exposed to the incident radiation, both direct solar radiation and long-wave radiation from heated surfaces. The shield interacts with the atmosphere through convection (natural on the outer surface and forced on the inner) and radiation and with the sensor only through radiation. The sensor interacts with the atmosphere through forced convection.

If the fan is off, the whole system attains a steady state where all the components attain the same temperature after a long time. The equations governing the process are as given in the "Appendix".

Table 1. Simulated temperature error in still air.

\begin{tabular}{lcc}
\hline Sensor & $\begin{array}{c}\text { Temperature } \\
\text { reading (K) }\end{array}$ & $\begin{array}{c}\text { Error } \\
(\mathrm{K})\end{array}$ \\
\hline $\begin{array}{l}\text { Thermocouple without shielding } \\
\text { (cylinder) }\end{array}$ & 302.08 & 2.08 \\
$\begin{array}{l}\text { Thermocouple without shielding } \\
\text { (sphere) }\end{array}$ & 301.1 & 1.1 \\
\begin{tabular}{l} 
Sensirion without shielding \\
\hline
\end{tabular} & 312.34 & 12.34 \\
\hline
\end{tabular}

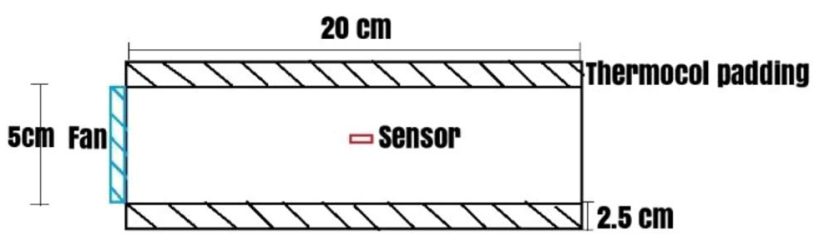

Figure 2. Schematic of the aspirated set-up (not to scale).
Table 2. Model parameters.

\begin{tabular}{lc}
\hline Parameter & Value \\
\hline Insolation & $500 \mathrm{~W} / \mathrm{m}^{2}$ \\
Ambient temperature & $300 \mathrm{~K}$ \\
Absorptivity of sensors & 0.5 \\
Thermocol thickness & $2.5 \mathrm{~cm}$ \\
\hline
\end{tabular}

\subsection{Results of the model}

The equations were solved numerically in $\mathrm{C}++$ to get the values of sensor temperature for different parameters.

Here, the results shown are those considering parameters as shown in table 2. The Sensirion was modelled as a $5 \mathrm{~mm} \times 3 \mathrm{~mm}$ flat plate. The thermocouple was modelled as two cases-one as a cylinder with $1 \mathrm{~mm}$ diameter and $3 \mathrm{~mm}$ length, and the other as a sphere of $1 \mathrm{~mm}$ diameter.

We present results for the case of sensor placed within the shield and with the fan on. Once the fan is turned on, the temperature errors drop significantly in both the thermocouple (error is small to begin with) as well as the Sensirion. The results are shown in figure 3 for different velocities induced by the fan. The results are shown for the Sensirion model only.

Even a small velocity drastically reduces the temperature the sensor sees from 312 to around $301 \mathrm{~K}$. When ambient air is forced through the set-up, the inner surface of the shield and the sensor exchanges heat through forced convection with the ambient air, and this greatly reduces their steady state temperatures. Thus, even small flow rates of air are sufficient to reduce significant errors. However, increasing velocity of the air does not reduce the error substantially as seen in figure 3 .

Dependence of temperature error on insolation is shown in figure 4 . Here, the velocity is kept constant at $0.25 \mathrm{~m} / \mathrm{s}$ along with the other parameters. A linear relationship is observed.

\section{Experiments}

Experiments were conducted to validate the model and to understand the impact of radiation shields with and without aspiration on temperature measurement. To obtain windless conditions and replicate conditions obtained in a greenhouse, a model polyhouse was built on the rooftop of the Department of Mechanical Engineering at IISc, Bangalore. The polyhouse is shown in figure 5 .

To compare the temperature values with shielding and aspiration, a horizontal tube shield along with unshielded sensors was used. The horizontal PVC tube shield $(5 \mathrm{~cm}$ diameter) was insulated with $2.5 \mathrm{~cm}$ thick thermocol and wrapped in aluminium foil. A 0.09-A fan, SUNON model KD1204KBX-8, was attached to the end of the PVC tube and provided a mean speed of $1 \mathrm{~m} / \mathrm{s}$. 


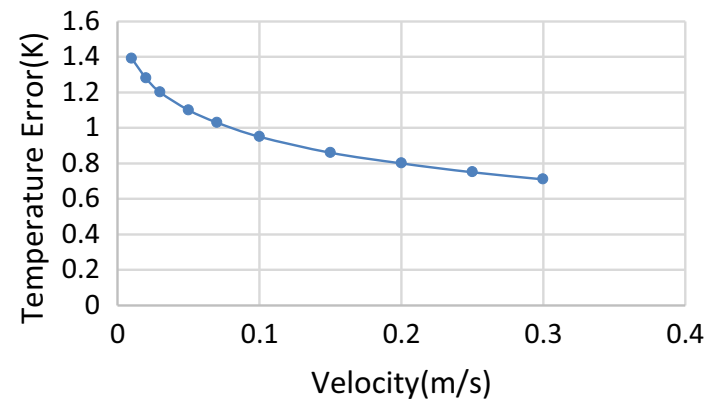

Figure 3. Temperature error versus velocity for $500 \mathrm{~W} / \mathrm{m}^{2}$ insolation.

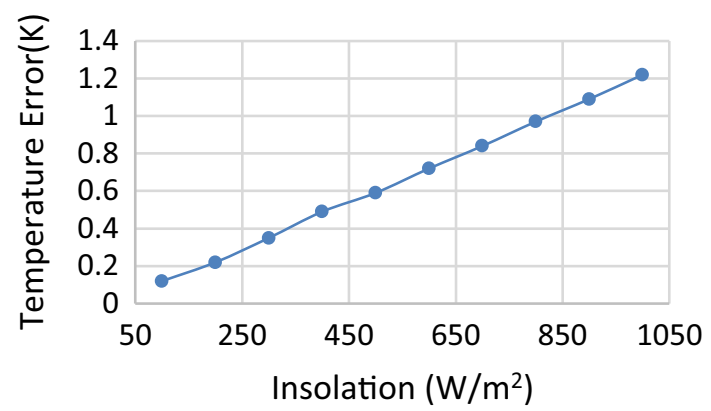

Figure 4. Temperature error versus Insolation for velocity of $0.25 \mathrm{~m} / \mathrm{s}$.

Air temperature measurements were taken using T-type thermocouples of $1 \mathrm{~mm}$ diameter. One of the thermocouples was placed inside the Gill shield, one more inside the PVC tube, and one was placed inside the polyhouse without any shielding.

Global irradiance was measured using a pyranometer inside the polyhouse. For thermocouples and the pyranometer, data were captured using a Keysight Data Acquisition system (Model 4972 A) every $30 \mathrm{~s}$ and the data logger was housed inside a room kept at the ambient temperature outside the polyhouse. Measurements from all thermocouples and Sensirion sensors agreed to within $0.1^{\circ} \mathrm{C}$ when not under direct radiation. The temperature from the SHT 75 sensor was logged onto an Arduino Mega 2560 microprocessor, which was also housed inside the room.

\subsection{Solar chimney}

The fan used in the experiments produced an average velocity of $1 \mathrm{~m} / \mathrm{s}$. However, it was shown in the model that such high velocities are not required to reduce the temperature error significantly. This was the main motivation behind finding a new method to cool the sensor without using a fan. The concept of a solar chimney has been used for a long time in power generation [5] and in architecture as a means to provide ventilation [6].

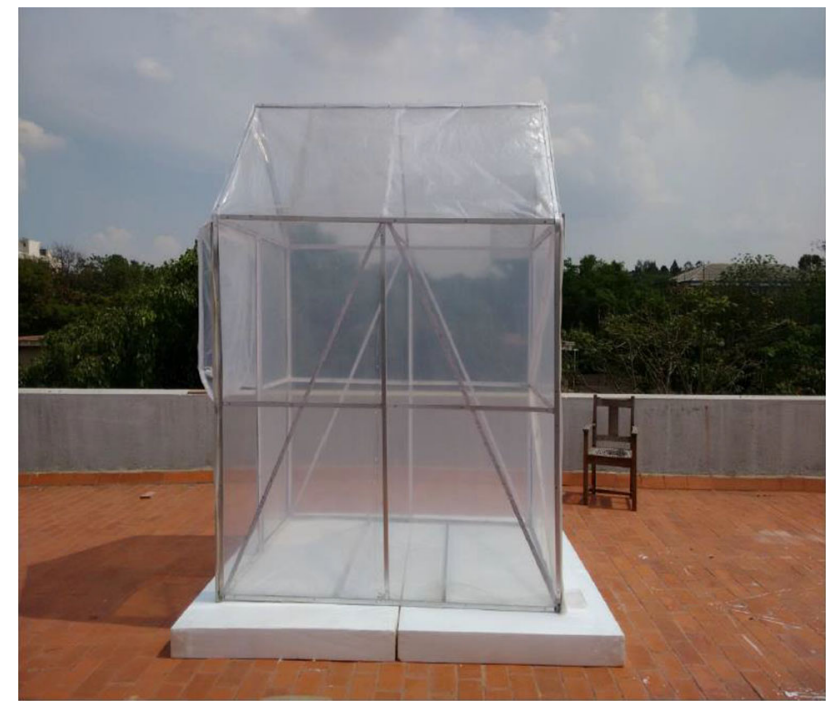

Figure 5. Polyhouse inside which experiments were conducted.

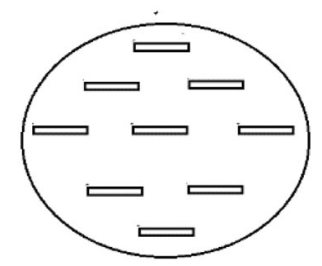

Figure 6. Top view of solar chimney model with strips arranged inside a transparent cylinder.

Different designs of the solar chimney were tried to understand which type would induce high flow rates and would thus reduce the error shown by the sensors.

The first type included the conventional single wall single transparent vertical surface as shown in figure 3 of [7]. The second design included using absorber strips instead of a single wall to induce uniform heating within the solar chimney. A third design included using rods instead of strips. The arrangement of vertical strips inside a cylindrical enclosure connected to the sensor housing is shown in figure 6 . This arrangement gave the least errors in temperature measurement.

It would be impractical to build a solar chimney that is too large considering that it must provide aspiration to only one small sensor. It is therefore important to calculate the flow rate provided by a small chimney to see if it produces enough mass flow rate to reduce the temperature error of the sensors. The final set-up is shown in figure 7.

The mass flow rate for a solar chimney configuration with one wall is calculated using the following formula [8]:

$$
m=\frac{C_{D} \rho_{i} A_{0}}{\sqrt{1+\left(\frac{A_{0}{ }^{2}}{A_{i}}\right)}} \sqrt{2 g H\left(\frac{T_{i}}{T_{0}}-1\right)} .
$$

The average fluid temperature is calculated using an energy balance as described in [8] with a few simplifying 


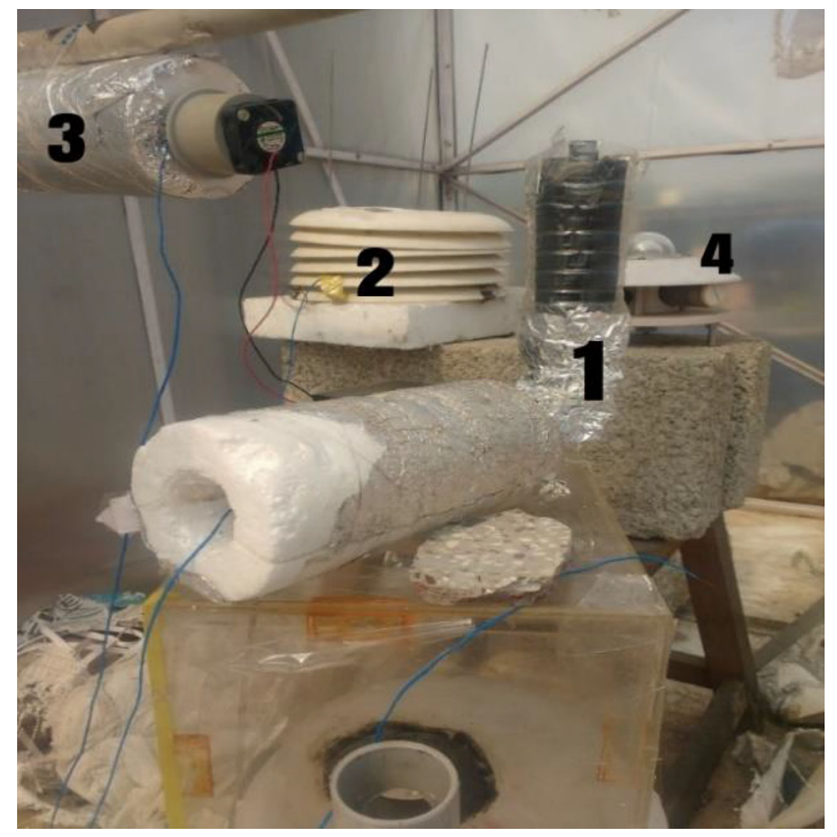

Figure 7. The different sensors inside the polyhouse. 1-Solarchimney-assisted aspiration, 2-Gill radiation shield, 3-fanassisted aspiration, 4-pyranometer.

Table 3. Mass flow rates for different wall heights.

\begin{tabular}{lccc}
\hline Height $(\mathrm{m})$ & Width $(\mathrm{m})$ & Flow rate $(\mathrm{cfm})$ & Velocity $(\mathrm{m} / \mathrm{s})$ \\
\hline 0.10 & 0.05 & 0.30 & 0.07 \\
0.10 & 0.10 & 0.36 & 0.088 \\
0.15 & 0.075 & 0.43 & 0.10 \\
0.20 & 0.10 & 0.57 & 0.13 \\
\hline
\end{tabular}

assumptions: namely the model was solved considering one glass wall and one absorber wall without conductivity and also by assuming appropriate Nusselt numbers for the given geometry.
The equations are solved using an iterative method in $\mathrm{C}++$ to calculate the wall, glass and average fluid temperatures and the mass flow rate, and the results are shown in table 3. The solar insolation for all these cases was taken as $350 \mathrm{~W} / \mathrm{m}^{2}$.

As observed, small solar chimneys (less than $15 \mathrm{~cm}$ height and width less than $7 \mathrm{~cm}$ ) can induce the required small flow rates. Experiments were conducted that had a single wall as was calculated, and for strips as shown in figure 6. It was found that the strips were more effective although no analytical calculation of the flow rate was performed. The principle, however, remains the same and all the results are for the vertical strips.

\section{Experimental results}

\subsection{Results for thermocouple}

Figure 8 shows the temperature values recorded on a cloudless day from 11 am to $4 \mathrm{pm}$ using two thermocouples - one shielded with the fan and another unshielded. The fan was switched on at 1:30 pm and is characterized by a sudden drop in temperature for the thermocouple in the shield. As predicted by the model, the thermocouple that was not shielded recorded higher temperatures than the aspirated thermocouple by $1-1.5 \mathrm{~K}$ under high solar insolation $\left(>500 \mathrm{~W} / \mathrm{m}^{2}\right)$. Thus, the thermocouple that is shielded and sufficiently aspirated is assumed to show the most accurate reading for all the experiments. It can also be seen that without aspiration, the shielded thermocouple shows a temperature significantly higher than that of the unshielded one (up to $7 \mathrm{~K}$ ). It is also worth noting that the unshielded thermocouple, because of its low thermal mass as compared with the whole shielding set-up, is more sensitive to changes in insolation and hence the graph for the unshielded thermocouple shows rapid variations corresponding to

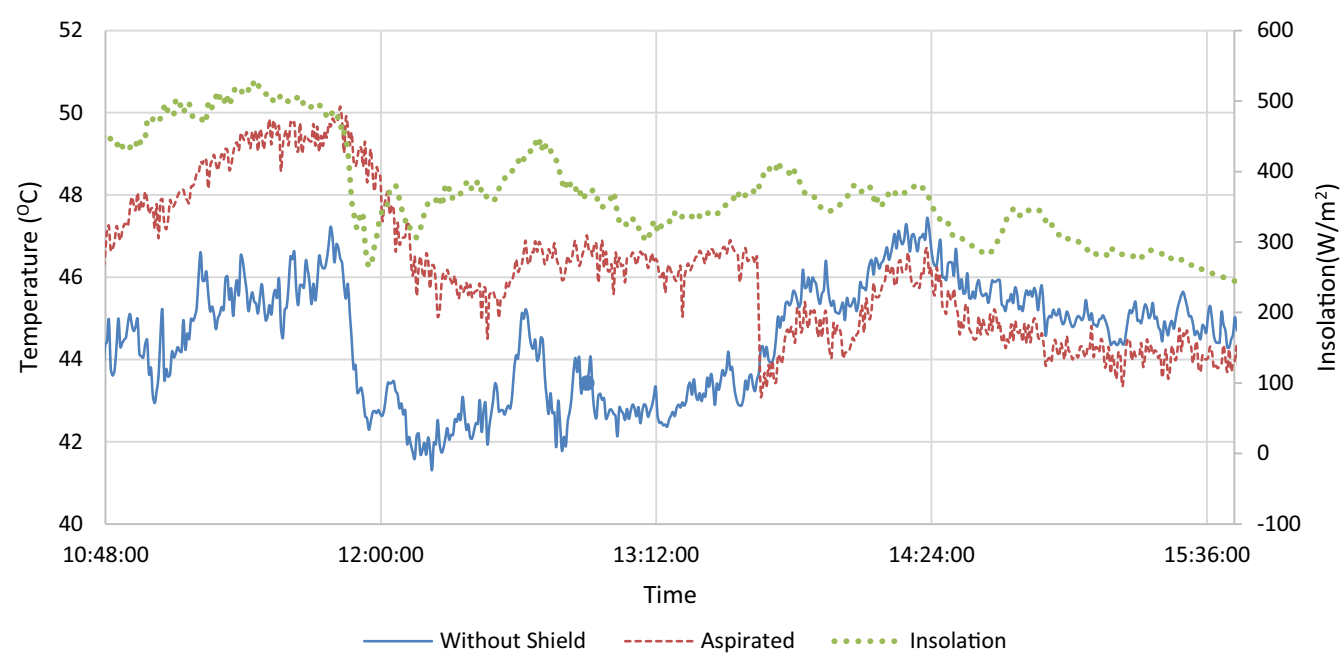

Figure 8. Temperature readings of thermocouples, one unshielded and the other placed in the aspirated tube. The fan is switched on at $1: 30 \mathrm{pm}$. 


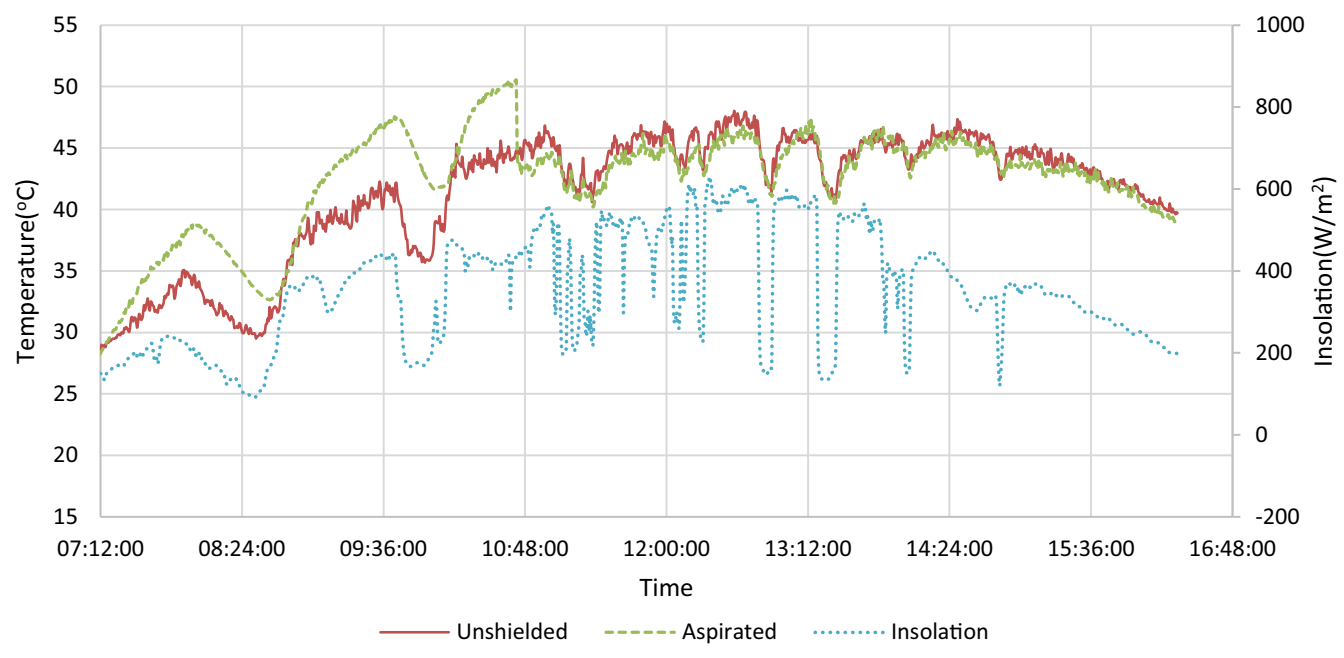

Figure 9. Temperature readings of two thermocouples with changing insolation. Fan is switched on at 10:45 am.

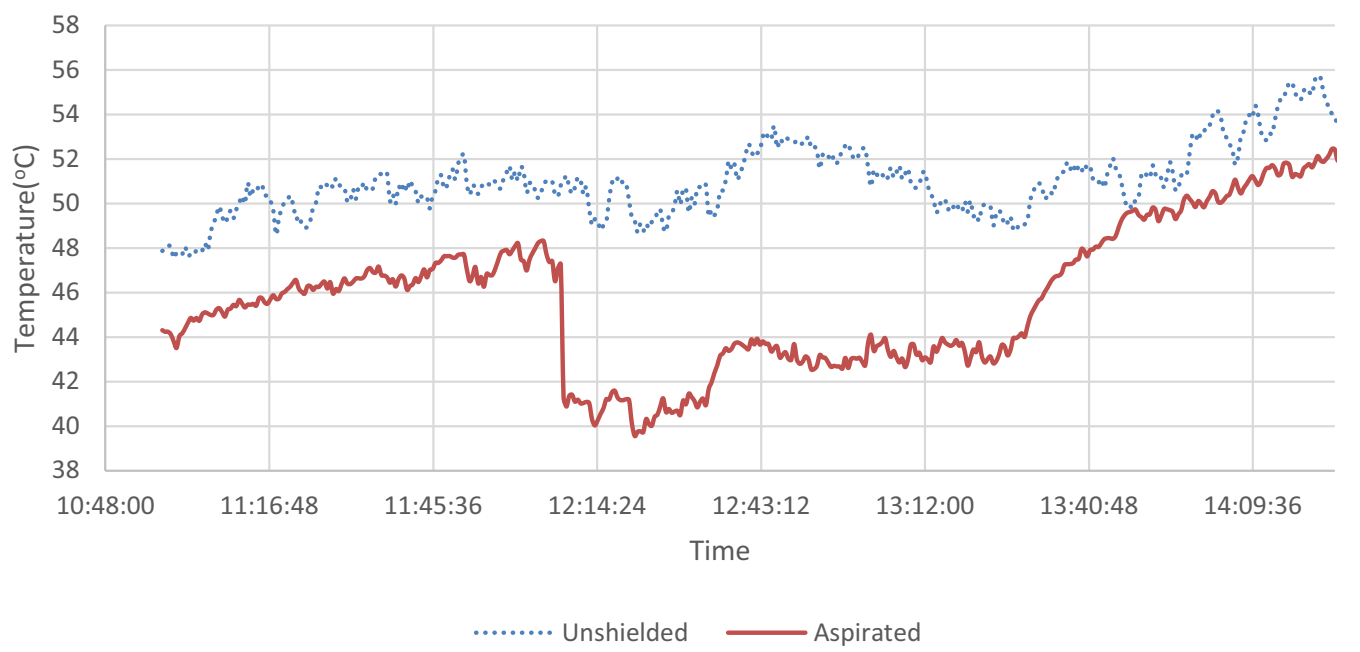

Figure 10. Temperature values for two Sensirion sensors (one unshielded and the other shielded and aspirated). Fan switched on at 12:10 and switched off at 13:20. No insolation data was available for this measurement.

the changes in the insolation. Due to the rapidly changing insolation, sometimes the aspirated and unshielded temperatures show the same value. However, on average the aspirated sensor shows a lower reading, especially when the insolation is relatively stable. This difference can be seen clearly in figure 9, where the data were taken on a day with intermittent insolation due to clouds. The unshielded thermocouple rapidly changes temperature and even though it is still discernible that the aspirated thermocouple shows lower temperatures, the difference is less than $1 \mathrm{~K}$ due to the rapidly changing insolation. From the graphs, it can be observed that the temperatures inside the polyhouse are relatively high and go up to $50^{\circ} \mathrm{C}$.

\subsection{Results for Sensirion}

As the Sensirion has a higher surface area exposed to the radiation, it was predicted by the model that the temperature error produced would be around $12 \mathrm{~K}$. In the experiments, the unshielded Sensirion showed a temperature that was about $10 \mathrm{~K}$ higher than the aspirated one. The graph for the Sensirion sensor is shown in figure 10. The shielded sensor with the fan off showed $2-4^{\circ} \mathrm{C}$ lower than the unshielded one.

\subsection{Results for solar chimney}

The results obtained for the solar chimney are shown in figure 11. It was found that the use of strips was more effective than the single wall solar chimney.

It was also observed that the temperature recorded by the Sensirion sensor with the solar chimney was around $1-1.5 \mathrm{~K}$ higher than that by the aspirated sensor. This is expected from the model; a slower mass flow rate causes the temperature error to be higher. 


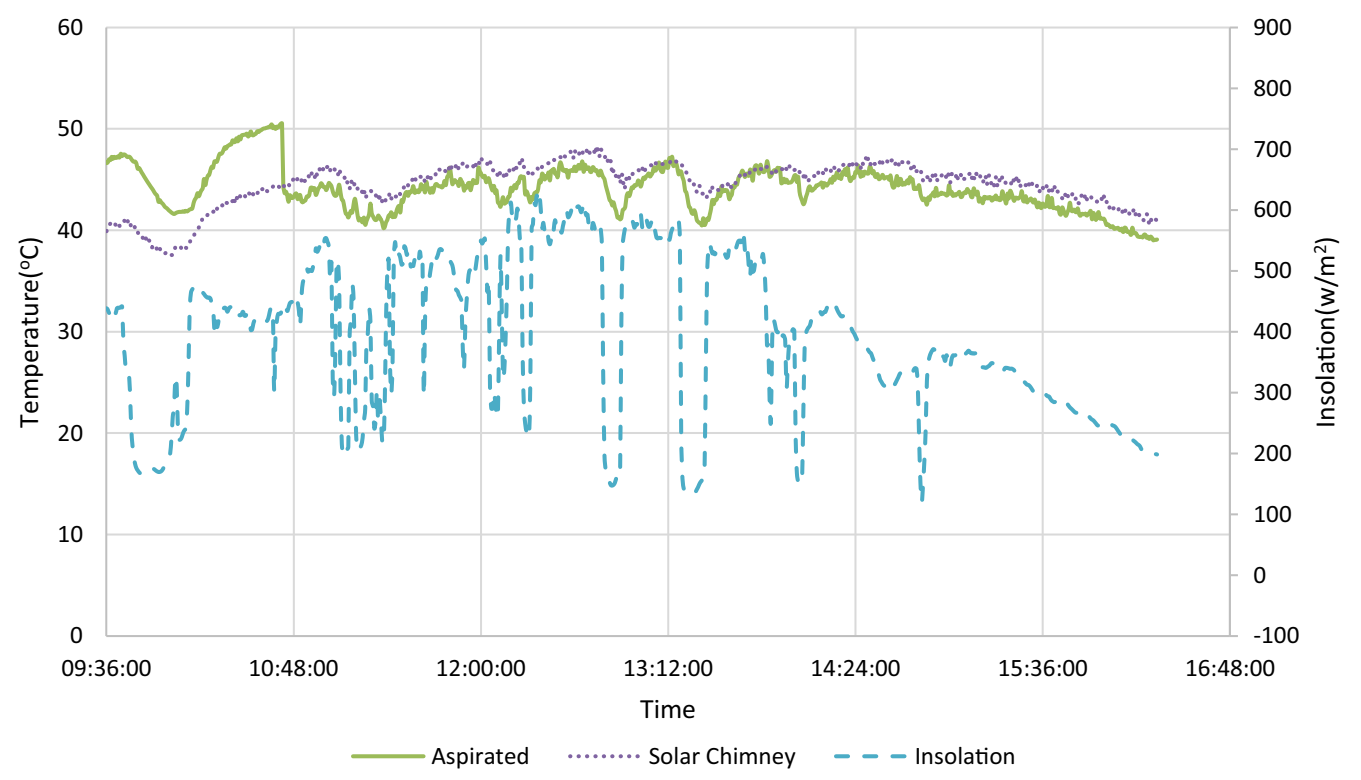

Figure 11. Temperature values for aspirated thermocouple and solar-chimney-aspirated sensor. Fan switched on at 10:50 am.

\section{Conclusion}

It is clearly understood that in environments where there is no movement of air, errors in temperature measurement may be too large to ignore. It is thus very important to aspirate the sensors to reduce this error. It has been shown that even small flow rates are relatively successful in reducing the error shown by temperature sensors inside high radiation environments. The use of standard radiation shields like the Gill shield without any aspiration will cause significant errors in the temperature readings.

The concept of using a solar chimney instead of a fan has been introduced and it has been shown that a solar chimney can be used instead of fans to a reasonable accuracy. Further improvements in the design of the solar chimney are possible to ensure higher flow rates, thus lowering the errors further.

It is also worth noting that solar chimneys need to be placed in areas with reasonably high solar insolation.

\section{Nomenclature}

I solar insolation

$A_{p} \quad$ perpendicular area

$\alpha \quad$ absorptivity

$\alpha_{d} \quad$ thermal conductivity

$U$ overall heat transfer coefficient

$h \quad$ convective heat transfer coefficient

$T_{s s} \quad$ sensor surface temperature

$T_{a}$ ambient temperature

$C_{D}$ discharge coefficient

$A_{o} \quad$ outlet cross-sectional area

$A_{i} \quad$ inlet cross-sectional area

$H$ height of absorbing wall

$\rho_{i} \quad$ average fluid density

$T_{i} \quad$ average fluid temperature inside chimney
$T_{o} \quad$ average fluid temperature outside chimney

$m$ mass flow rate

$g \quad$ acceleration due to gravity

$k$ thermal conductivity

$r$ radius

$F \quad$ radiation view factor

$h$ heat transfer coefficient

$\mathrm{Nu} \quad$ Nusselt number

$\mathrm{Ra}$ Rayleigh number

Re Reynolds number

Pr Prandtl number

$\Delta T$ temperature difference

$l \quad$ characteristic length

$\beta \quad$ thermal expansion coefficient

$v \quad$ kinematic viscosity

\section{Subscripts used in appendix}

so shield outer

si shield inner

soa shield outer ambient

sia shield inner ambient

ss sensor surface

\section{Appendix}

In steady state, the outside surface of the shield is directly exposed to the atmospheric radiation. The heat absorbed by the outer surface is convected and radiated to the atmosphere and also conducted to the inner surface of the thermocol and PVC tube (assuming no contact resistance and zero thickness of the PVC tube). The PVC tube then radiates heat to the sensor and also loses heat by 
convection due to the fan. The sensor, in turn, loses heat to convection.

Equation (A1) models the energy balance for the outer thermocol insulation. Equation (A2) equates the energy conducted to the inner surface of the insulation and then radiated to the sensor. Equation (A3) is the energy balance over the sensor considering forced ventilation.

$$
\begin{aligned}
& I A_{s o p} \alpha=\frac{2 \pi k_{s o} L\left(T_{s o}-T_{s i}\right)}{\ln \left(\frac{r_{o}}{r_{i}}\right)}+h_{s o a} A_{s o}\left(T_{s o}-T_{a}\right) \\
& +\sigma A\left(T_{s o}^{4}-T_{a}^{4}\right) \\
& \frac{2 \pi k_{s o} L\left(T_{s o}-T_{s i}\right)}{\ln \left(\frac{r_{o}}{r_{i}}\right)}=h_{s i a} A_{s i}\left(T_{s i}-T_{a}\right) \\
& +\sigma A_{s i} F_{s s} \alpha_{s s}\left(T_{s i}^{4}-T_{s s}^{4}\right), \\
& \sigma A_{s i} F_{s s} \alpha_{s s}\left(T_{s i}^{4}-T_{s s}^{4}\right)=h_{s s a} A_{s s}\left(T_{s s}-T_{a}\right) .
\end{aligned}
$$

Here, $A, k, T, h, r$ and $F$ stand for the area, thermal conductivity, temperature, heat transfer coefficient, radius and radiation view factor, respectively, while the subscripts so, si, soa, sia and ss stand for shield outer, shield inner, shield outer ambient, shield inner ambient and sensor surface, respectively.

The Nusselt number correlations for hsoa, hsia and hssa are the horizontal cylinder natural convection, pipe internal convection and horizontal plate in forced convection, respectively.

1. Horizontal flat plate in natural convection

$$
\begin{gathered}
R a=\frac{g \beta \times \Delta T \times l^{3}}{v \alpha_{d}} \\
N u=0.54 R a^{0.25}
\end{gathered}
$$

2. Horizontal cylinder in natural convection $\left(R a_{D}<10^{12}\right)$

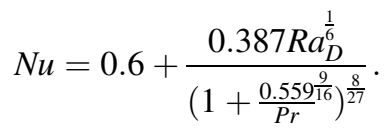

3. Horizontal sphere in natural convection $\left(R a_{D}<10^{11}\right)$.

$$
N u=2+\frac{0.589 R a_{D}^{1 / 4}}{\left(1+{\frac{0.469^{9 / 16}}{P r}}^{4 / 9}\right.} .
$$

4. Flat plate in forced convection

For the sensor in a mean flow velocity of $1 \mathrm{~m} / \mathrm{s}$ and polyhouse conditions, the flow is assumed to be laminar (it should be noted that the fan is sucking air over the sensor as opposed to blowing).

$$
N u=0.664 \operatorname{Re}^{\frac{1}{2}} \operatorname{Pr}^{\frac{1}{3}} .
$$

5. Forced convection from tube at constant temperature

$$
N u=3.66 \text {. }
$$

\section{References}

[1] Fuchs M and Tanner C B 1965 Radiation shields for air temperature thermometers. J. Appl. Metrol. 4: 544-547

[2] Nakumara R and Mahrt L 2005 Air temperature measurement errors in naturally ventilated radiation shields. J. Atmos. Ocean. Technol. 22: 1046-1058

[3] Holden A Z, Klene A E, Keefe R F and Moisen G G 2013 Design and evaluation of inexpensive radiation shield for monitoring surface air temperatures. Agric. For. Meteorol. 180: $281-286$

[4] Hubbard K G, Lin X and Walter-Shea E A 2001 The effectiveness of the ASOS, MMTS, Gill and CRS air temperature radiation shields. J. Atmos. Ocean. Technol. 18: 851-864

[5] Schlaic J, Bergermann R, Schiel W and Weinrebe G 2015 Design of commercial solar updraft tower systems-utilization of solar induced convective flows for power generation. $J$. Solar Energy Eng. 127: 117-124

[6] Bassiouny R and Koura N S A 2008 An analytical and numerical study of solar chimney use for room natural ventilation. Energy Build. 40: 865-873

[7] Shi L and Chew M Y L 2012 A review on sustainable design of renewable energy systems. Renew. Sustain. Energy Rev. 16: 192-207

[8] Bansal N K, Mathur R and Bhandari M S 1993 Solar chimney for enhanced stack ventilation. Build. Environ. 28(3): 373-377 